\title{
The Hypervirulent Strain of Clostridium Difficile: NAP1/B1/027 - A Brief Overview
}

Rawish Fatima ${ }^{1}$, Muhammad Aziz ${ }^{2}$

1. Internal Medicine, Dow University of Health Sciences, Karachi, PAK 2. Internal Medicine, University of Kansas Medical Center, Kansas City, USA

Corresponding author: Muhammad Aziz, maziz2@kumc.edu

\begin{abstract}
Clostridium difficile is a gram-positive bacterium notorious for causing epidemic diarrhea globally with a significant health burden. The pathogen is clinically challenging with increasing antibiotic resistance and recurrence rate. We provide here an in-depth review of one particular strain/ribotype 027, commonly known as NAP1/B1/027 or North American pulsed-field gel electrophoresis type 1, restriction endonuclease analysis type B1, polymerase chain reaction ribotype 027 , which has shown a much higher recurrence rate than other strains.
\end{abstract}

Categories: Internal Medicine, Gastroenterology, Infectious Disease

Keywords: clostridium difficile, diarrhea, ribotype 027, recurrence, nap1/b1/027

\section{Introduction And Background}

Clostridium difficile (C. diff) is a gram-positive, anaerobic, motile, spore-forming, rod-shaped bacteria [1-2]. It has been isolated from almost all mammals, including pigs, cows, horses, elephants, and Kodiak bears, as well as in poultry and ostriches. It has also been found in the soil and feces of humans and animals. It is transmitted from person to person by the fecal-oral route. The C. diff isolates found in animals are similar to the ones found in humans, but according to Hensgens et al., this similarity does not mean that interspecies transmission occurs. However, immunocompromised people are still at risk for interspecies transmission [1]. Its pathogenicity is dependent on the two toxins that it produces: enterotoxin A (Toxin A or TcdA) and cytotoxin B (Toxin B or TcdB). Enterotoxin damages the actin in target cells which leads to neutrophil infiltration, inflammation, and necrosis of epithelial cells. Cytotoxin B has been shown to damage tight junctions of epithelial cells, which increases vascular permeability and causes hemorrhage [2-3]. These toxins form the basis of stool analysis when diagnosing people with the suspected infection. Despite all the virulence characters described, C. diff is a poor competitor against other gut flora in the human colon. In a healthy colon, this pathogen is not in sufficient quantity to produce a clinically significant disease. Risk factors that disrupt this balance include antibiotics exposure, health care environment, acid suppressants, and elemental diet. The bacterium can cause severe watery diarrhea that can progress to

Received 12/27/2018

Review began 01/19/2019 Review ended 01/22/2019 Published 01/29/2019

\section{() Copyright 2019}

Fatima et al. This is an open access article distributed under the terms of the Creative Commons Attribution License CC-BY 3.0., which permits unrestricted use, distribution, and reproduction in any medium, provided the original author and source are credited. pseudomembranous colitis [3-8]. It has been named as one of the three microorganisms with an 'urgent' threat level by the Centers for Disease Control and Prevention (CDC) based on its public health impact in the United States (US) with an estimated \$1.5 billion US in annual health care expenditures [8]. Patients who have more than three episodes of unexplained and new onset unformed stools in 24 hours should be referred for testing for a Clostridium difficile infection (CDI). Also, patients with risk factors described previously should undergo testing for this pathogen [9]. The ribotype 027 strain of C. diff is particularly noteworthy as contradicting evidence in the literature is present regarding the disease severity it causes. We provide here a brief overview of the epidemiology, pathophysiology, and treatment of this particular strain.

\section{Review}

\section{Ribotypes and prevalence of Clostridium difficile (C. diff)}

Clostridium difficile can be characterized according to its ribotyping which is performed using the polymerase chain reaction. Several different ribotypes have been associated with CDI. The ribotypes 001 , 002, 014, 046, 078, 126, and 140 have been found to be prevalent in the Middle East [10-12]. In Asia, ribotypes 001, 002, 014, 017, and 018 are more prevalent [13-15]. The predominant strains in Europe and North America include ribotypes 001, 014, 020, 027, and 078 [6]. The ribotype 027 (also referred to as NAP1/B1/027) has emerged in the last decade. Studies have underlined antimicrobial resistance as one of the causes of its epidemic outbreaks. Capillary electrophoresis (CE) ribotyping is used as the standard for characterization of C. diff isolates. This method relies on the intergeneric region variability between $16 \mathrm{~S}$ and $23 \mathrm{~S}$ ribosomal deoxyribonucleic acid (DNA) [16]. Ribotype 027 was found to have reduced susceptibility to metronidazole, rifampicin, moxifloxacin, clindamycin, imipenem, and chloramphenicol [17-18]. It is clinically and financially concerning as it leads to severe disease presentation, as well as antimicrobial resistance with high morbidity and mortality rates as compared to other strains [19]. Strains, such as ribotype 027 (especially its spores), spread more easily within the hospital because they can resist the hospital environment, cleaning, and disinfectants [1]. An observational study conducted on patients 
admitted with diarrhea in a Veteran Affairs Medical Center showed that around $22 \%$ of the patients were positive for the NAP1/B1/027 strain out of all the people who tested positive for CDI. Further, a reduction in the rate of diarrhea caused by the NAP1/B1/027 strain was observed with a prevalence of $16.9 \%$ in 2016, down from $26.2 \%$ in 2013. An increase in the level of awareness and education was thought to be the reason for this decline [20]. The prevalence of this strain in North America is reportedly around $22 \%-36 \%$. Ribotype 027 was identified as the most prevalent strain causing CDI with recent outbreaks in North America [20-22]. The prevalence of this strain was shown to be $48 \%$ in hospitals in Poland with an outbreak of CDI during September 2011 to August 2013 [21].

\section{NAP1/B1/027 strain}

Toxigenicity and Pathogenesis

The North American pulsed-field gel electrophoresis type 1, restriction endonuclease analysis type B1, polymerase chain reaction ribotype 027 (NAP1/B1/027) strain has been shown to contain a gene locus, CdtLoc, that encodes for CD196 ADP-ribosyltransferase (CDT) or binary toxin. The bacterium also produces Toxin A and Toxin B, similar to non-027 ribotypes, through the PaLoc gene locus [23-24]. CDT was first isolated by Popoff et al. [25]. The toxin comprises two separate toxin components: CDTa and CDTb. $\mathrm{CDTa}$, which is an ADP-ribosyltransferase enzyme, modifies actin which results in depolymerization and destruction of the actin cytoskeleton in the gut. CDTb binds to gut cells and increases uptake of CDTa. The destruction caused by CDT favors adherence of bacteria and increased uptake of Toxin A and Toxin B [26].

In addition to the toxins, this strain (along with few others) carries a base pair frameshift deletion at nucleotide 117 of the TcdC gene, which is a negative regulator of Toxins A and B. A mutation in this gene thus causes hyperexpression of toxins by this particular strain. Warny et al. showed that NAP1/B1/027 produces Toxin A approximately 16 times and Toxin B approximately 23 times more than the control strains [27]. One study also proposed that increased sporulation by this strain may also be associated with the increased spread of CDI [28]. The virulent factors associated with NAP1/B1/027 strain have been summarized in Table 1 .

\footnotetext{
\begin{tabular}{|c|c|c|}
\hline & Virulent factor & Mechanism \\
\hline 1. & $\begin{array}{l}\text { Toxin A (Enterotoxin A } \\
\text { or TcdA) }\end{array}$ & $\begin{array}{l}\text { Damages the actin in target cells which leads to neutrophil infiltration, inflammation, and necrosis of epithelial cells } \\
\text { [24]. }\end{array}$ \\
\hline 2. & $\begin{array}{l}\text { Ioxin B (Cytotoxin B } \\
\text { or TcdB) }\end{array}$ & Damages tight junctions of epithelial cells, which increases vascular permeability and causes hemorrhage [24]. \\
\hline 3. & CDTa toxin & $\begin{array}{l}\text { Modification of actin with ADP-ribosylation that results in actin depolymerization and destruction of the } \\
\text { cytoskeleton that assists in adherence of bacteria to gut epithelial cells [25-26]. }\end{array}$ \\
\hline 4. & CDTb toxin & Facilitates uptake of CDTa toxin into the gut epithelial lining [25-26]. \\
\hline 5. & Hypersporulation & Increases reproduction and spread of bacteria [28]. \\
\hline 6. & $\begin{array}{l}\text { TcdC gene mutation } \\
\text { (18-bp deletion) }\end{array}$ & $\begin{array}{l}\text { Increases the production of Toxin A and Toxin B by down-regulation of feedback inhibitor involved in suppressing } \\
\text { toxin production [27]. }\end{array}$ \\
\hline
\end{tabular}

\section{TABLE 1: Virulent factors associated with NAP1/B1/027 strain}

CDTa toxin: CD196 ADP-ribosyltransferase a toxin; CDTb toxin: CD196 ADP-ribosyltransferase b toxin; NAP1/B1/027: North American pulsed-field gel electrophoresis type 1, restriction endonuclease analysis type B1, polymerase chain reaction ribotype 027
}

Previous studies have shown contradicting evidence regarding the severity of disease caused by this particular strain. A recent retrospective analysis by Bauer et al. concluded that NAP1/B1/027 was associated with a decreased odds of severe disease (odds ratio (OR): 0.35 , 95\% confidence interval (CI) $0.13-0.93$ ) and did not increase in-hospital mortality (OR: 1.02, 95\% CI 0.53 - 1.96) or recurrence rate (OR: 1.16, 95\% CI 0.36 - 3.77) [23]. Several other studies conducted (including cross-sectional, case-control, and cohort studies) did not show any worse outcomes compared to other strains [29-31]. Sirad et al. demonstrated that although NAP1/B1/027 strain may produce more toxins compared to other strains, they produced fewer spores and were not always associated with severe disease [32]. On the contrary, Rao et al. conducted a cohort study and concluded that ribotype 027 was associated with severe CDI (OR: 1.73, 95\% CI $1.03-2.89 ; \mathrm{p}=0.037$ ) and increased mortality (OR: 2.02, 95\% CI $1.19-3.43 ; \mathrm{p}=0.009$ ) compared to other ribotypes [24]. Another study showed similar results with the North American pulsed-field gel electrophoresis type 1 (NAP1) strain. Multivariate regression analysis exhibited an increase in the severity of CDI with the NAP1 strain (OR: 1.66, 95\% CI: 1.90 - 2.54) and increased mortality (OR: 2.12, 95\% CI: 1.22 - 3.68) [33]. One study from Quebec 
The basis for these contradictory findings can be explained by several reasons, including study design, study population, sample size, the method of detection for C. diff, study setting, and unmeasured confounders. Given these contradictory results, healthcare providers should focus on treating this infection based on their clinical judgment and markers of severe infection, including the number of diarrheal episodes, signs of dehydration, creatinine level, albumin level, white blood cell count, associated co-morbidities, immunocompromised state, etc.

Prevention

Preventive strategies employed for NAP1/B1/027 strain are similar to strategies taken for other strains. These include barrier methods (gloves and gown while examining patient), use of disposable equipment, handwashing with soap and water, disinfecting the environment, and antimicrobial stewardship [35]. Further vaccines are being developed targeting the toxins, including TcdA and TcdB, for simultaneous prevention and treatment of CDI. Actoxumab and bezlotoxumab, which are monoclonal antibodies against TcdA and TcdB, are being investigated for this purpose. A combined Phase III trial (MODIFY I (NCT01241552) and MODIFY II (NCT01513239)) showed benefit from bezlotoxumab, but the combination of actoxumab and bezlotoxumab did not yield any further benefit [36]. Bezlotoxumab has received Food and Drug Administration (FDA) approval in October 2016 and is to be used in patients more than 18 years of age, who are at high risk of recurrence from CDI, and are receiving antibiotics [37]. A novel tetravalent vaccine against TcdA, TcdB, CDTa, and CDTb has been proposed by Secore et al. using a hamster model which has shown promising results [38].

A novel drug, SYN-004 (ribaxamase), is under investigation that has shown promising results for preventing CDI. This drug, which is a $\beta$-lactamase, is excreted into the gut and degrades the excess antibiotic that prevents disruption of normal gut flora, ultimately preventing CDI [39]. The Phase IIa clinical trial of this drug showed that ribaxamase at a dose of $150 \mathrm{mg}$ every six hours results in an undetectable concentration of ceftriaxone in the intestine which can potentially decrease the likelihood of a C. diff infection, given the less probability of disruption of the gut bacteria.

\section{Resistance to Antibiotics and Treatment}

Cases of NAP1/B1/027 reported in Panama were found to be highly resistant to clindamycin, moxifloxacin, levofloxacin, ciprofloxacin, and rifampin but were susceptible to metronidazole and vancomycin [40]. Susceptibility of ribotype 027 and non-027 ribotypes to different antibiotics was tested in a study in Canada. Ribotype 027 showed a resistance of $92.2 \%$ to moxifloxacin compared to $11.2 \%$ for other strains. Similarly, $78.2 \%$ of ribotype 027 strains were resistant to ceftriaxone compared to $15.7 \%$ of other strains. Ribotype 027 demonstrated a greater than four-fold higher minimum inhibitory concentration (MIC) to metronidazole (4 vs. $1 \mu \mathrm{g} / \mathrm{ml}$ ) and two-fold higher MIC for fidaxomicin ( $1 \mathrm{vs} .2 \mu \mathrm{g} / \mathrm{ml})$. For clindamycin and vancomycin, the resistance was similar in both groups [41].

Resistance to erythromycin is linked to mutations in the ribosomal methylase genes, whereas resistance to fluoroquinolones is due to a mutation in DNA gyrase. Resistance to rifamycin and fidaxomicin is attributed to ribonucleic acid (RNA) polymerase methylation. The presence of phenicol and lincosamide genes has been shown to cause resistance to linezolid. A study conducted in hospitals of Mexico showed some isolates of ribotype 027 to have reduced susceptibility to fidaxomicin despite the unavailability of this drug in Mexico and the patients being unexposed to it [42]. Antibiotics form the basis of treatment for the NAP1/B1/027 strain. Currently, no specific Infectious Diseases Society of America (IDSA) guidelines are available to guide treatment for this particular strain, and hence, the treatment is similar to a non-NAP1/B1/027 strain [9]. Based on the current guidelines for treating CDI overall, we propose the following table for treating infection caused by the NAP1/B1/027 strain (Table 2). 


\section{Cureus}

\begin{tabular}{|c|c|c|}
\hline & First line treatment & Alternative treatment \\
\hline $\begin{array}{l}\text { Initial non- } \\
\text { severe } \\
\text { infection }\end{array}$ & Oral vancomycin, $125 \mathrm{mg}$ four times daily for 10 days & $\begin{array}{l}\text { Fidaxomicin, } 200 \mathrm{mg} \text { twice daily for } 10 \\
\text { days; If neither is available, then use } \\
\text { metronidazole, } 500 \mathrm{mg} \text { three times daily for } \\
10 \text { days }\end{array}$ \\
\hline $\begin{array}{l}\text { First non- } \\
\text { severe } \\
\text { recurrence }\end{array}$ & Repeat oral vancomycin, $125 \mathrm{mg}$ four times daily for 10 days & Fidaxomicin, $200 \mathrm{mg}$ twice daily for 10 days \\
\hline $\begin{array}{l}\text { Second } \\
\text { non-severe } \\
\text { recurrence }\end{array}$ & $\begin{array}{l}\text { Oral vancomycin taper as follow: } 125 \mathrm{mg} \text { four times daily for seven to } 14 \text { days, } 125 \\
\mathrm{mg} \text { twice daily for seven days, } 125 \mathrm{mg} \text { twice once daily for seven days, } 125 \mathrm{mg} \text { once } \\
\text { every other day for seven days, } 125 \mathrm{mg} \text { once every three days for } 14 \text { days }\end{array}$ & $\begin{array}{l}\text { Fidaxomicin, } 200 \mathrm{mg} \text { orally twice daily for } \\
10 \text { days, or a fecal microbiota transplant }\end{array}$ \\
\hline $\begin{array}{l}\text { Subsequent } \\
\text { non-severe } \\
\text { recurrence }\end{array}$ & Fecal microbiota transplant & $\begin{array}{l}\text { Tapering oral vancomycin with probiotics, } \\
\text { IVIG, fidaxomicin }\end{array}$ \\
\hline $\begin{array}{l}\text { Severe } \\
\text { disease }\end{array}$ & $\begin{array}{l}\text { Oral vancomycin, } 125 \mathrm{mg} \text { four times daily, increase to } 500 \mathrm{mg} \text { four times daily if no } \\
\text { improvement noted in } 24-48 \text { hours or associated complications, including renal } \\
\text { failure, ileus, etc. }\end{array}$ & $\begin{array}{l}\text { Fidaxomicin if the patient cannot tolerate } \\
\text { oral vancomycin for any reason }\end{array}$ \\
\hline lleus & $\begin{array}{l}\text { Add IV metronidazole, } 500 \mathrm{mg} \text { every eight hours, to oral vancomycin or fidaxomicin } \\
\text { therapy; consider general surgery consult as needed }\end{array}$ & Intracolonic vancomycin, IVIG \\
\hline $\begin{array}{l}\text { V: intravenous } \\
\text { analysis type } \mathrm{E}\end{array}$ & $\begin{array}{l}\text {; IVIG: intravenous immunoglobulin; NAP1/BI/027: North American pulsed-field gel ele } \\
\text { B1, polymerase chain reaction ribotype } 027\end{array}$ & trophoresis type 1, restriction endonuclease \\
\hline
\end{tabular}

This strain has not shown any resistance to fidaxomicin, but there has been some contradicting evidence to this. A case report was published in 2017 in which the NAP1 C. diff infection, resistant to treatment with fidaxomicin and fecal transplants, was effectively treated with intravenous immunoglobulin (IVIG) [43] . Given the emerging threat of antibiotic resistance, increasing awareness, controlling infections, and antimicrobial stewardship can be effective measures to reduce this threat [17].

Currently, several novel antibiotics are under investigation which have gone through various randomized controlled trials for CDI treatment. Ridinilazole and cadazolid have completed Phase II trials, while surotomycin has completed two Phase III trials which have shown promising results [44-47].

\section{Conclusions}

The data regarding the NAP1/B1/027 strain is inconclusive with ongoing debates whether this particular strain is associated with severe disease. Further research, including meta-analyses, are needed to solve this enigma. Clinicians should guide treatment based on their judgment and objective evidence of disease severity.

\section{Additional Information \\ Disclosures}

Conflicts of interest: In compliance with the ICMJE uniform disclosure form, all authors declare the following: Payment/services info: All authors have declared that no financial support was received from any organization for the submitted work. Financial relationships: All authors have declared that they have no financial relationships at present or within the previous three years with any organizations that might have an interest in the submitted work. Other relationships: All authors have declared that there are no other relationships or activities that could appear to have influenced the submitted work.

\section{References}

1. Hensgens MP, Keessen EC, Squire MM, et al.: Clostridium difficile infection in the community: a zoonotic disease?. Clin Microbiol Infect. 2012, 18:635-45. 10.1111/j.1469-0691.2012.03853.x

2. Aziz M, Fatima R, Douglass L, Abughanimeh O, Raza S: Current updates in management of Clostridium difficile infection in cancer patients. Curr Med Res Opin. 2018, Epub ahead of print:1-6. 10.1080/03007995.2018.1487389

3. Sachsenheimer FE, Yang I, Zimmermann O, et al.: Genomic and phenotypic diversity of Clostridium difficile 
during long-term sequential recurrences of infection. Int J Med Microbiol. 2018, 308:364-77. 10.1016/j.ijmm.2018.02.002

4. Luciano JA, Zuckerbraun BS: Clostridium difficile infection: prevention, treatment, and surgical management. Surg Clin North Am. 2014, 94:1335-49. 10.1016/j.suc.2014.08.006

5. Clabots CR, Johnson S, Olson MM, Peterson LR, Gerding DN: Acquisition of Clostridium difficile by hospitalized patients: evidence for colonized new admissions as a source of infection. J Infect Dis. 1992, 166:561-67. 10.1093/infdis/166.3.561

6. Howell M, Novack V, Grgurich P, Soulliard D, Novack L, Pencina M, Talmor D: Iatrogenic gastric acid suppression and the risk of nosocomial Clostridium difficile infection. Arch Intern Med. 2010, 170:784-90. 10.1001/archinternmed.2010.89

7. O'Keefe S: Tube feeding, the microbiota, and Clostridium difficile infection. World J Gastroenterol. 2010, 16:139-42. 10.3748/wjg.v16.i2.139

8. Hampton T: Report reveals scope of US antibiotic resistance threat. JAMA. 2013, 310:1661-63. 10.1001/jama.2013.280695

9. McDonald LC, Gerding DN, Johnson S, et al.: Clinical practice guidelines for Clostridium difficile infection in adults and children: 2017 update by the Infectious Diseases Society of America (IDSA) and Society for Healthcare Epidemiology of America (SHEA). Clin Infect Dis. 2018, 66:e1-e48. 10.1093/cid/cix1085

10. Jamal W, Rotimi VO, Brazier J, Duerden BI: Analysis of prevalence, risk factors and molecular epidemiology of Clostridium difficile infection in Kuwait over a 3-year period. Anaerobe. 2010, 16:560-65. 10.1016/j.anaerobe.2010.09.003

11. Jalali M, Khorvash F, Warriner K, Weese J: Clostridium difficile infection in an Iranian hospital . BMC Res Notes. 2012, 5:159. 10.1186/1756-0500-5-159

12. Al-Thani AA, Hamdi WS, Al-Ansari NA, Doiphode SH, Wilson GJ: Polymerase chain reaction ribotyping of Clostridium difficile isolates in Qatar: a hospital-based study. BMC Infect Dis. 2014, 14:502. 10.1186/14712334-14-502

13. Sawabe E, Kato H, Osawa K, Chida T, Tojo N, Arakawa Y, Okamura N: Molecular analysis of Clostridium difficile at a university teaching hospital in Japan: a shift in the predominant type over a five-year period. Eur J Clin Microbiol Infect Dis. 2007, 26:695-703. 10.1007/s10096-007-0355-8

14. Cheng V, Yam W, Lam O, et al.: Clostridium difficile isolates with increased sporulation: emergence of PCR ribotype 002 in Hong Kong. Eur J Clin Microbiol Infect Dis. 2011, 30:1371-81. 10.1007/s10096-011-1231-0

15. Kim H, Lee Y, Moon H, Lim C, Lee K, Chong Y: Emergence of Clostridium difficile ribotype 027 in Korea . Korean J Lab Med. 2011, 31:191-96. 10.3343/kjlm.2011.31.3.191

16. Krutova M, Nyc O, Matejkova J, Kuijper E, Jalava J, Mentula S: The recognition and characterisation of Finnish Clostridium difficile isolates resembling PCR-ribotype 027. J Microbiol Immunol Infect. 2018, 51:344-51. 10.1016/j.jmii.2017.02.002

17. Freeman J, Vernon J, Pilling S, et al.: The ClosER study: results from a three-year pan-European longitudinal surveillance of antibiotic resistance among prevalent Clostridium difficile ribotypes, 20112014. Clin Microbiol Infect. 2018, 24:724-31. 10.1016/j.cmi.2017.10.008

18. Goldstein EJ, Citron DM, Sears P, Babakhani F, Sambol SP, Gerding DN: Comparative susceptibilities of fidaxomicin (OPT-80) of isolates collected at baseline, recurrence, and failure from patients in two fidaxomicin phase III trials of fidaxomicin against Clostridium difficile infection. Antimicrob Agents Chemother. 2011, 55:5194-99. 10.1128/AAC.00625-11

19. Camacho-Ortiz A, López-Barrera D, Hernández-García R, et al.: Correction: First report of Clostridium difficile NAP1/027 in a Mexican hospital. PLoS One. 2015, 10:e0129079. 10.1371/journal.pone.0129079

20. Giancola S, Williams R, Gentry C: Prevalence of the Clostridium difficile BI/NAP1/027 strain across the United States Veterans Health Administration. Clin Microbiol Infect. 2018, 24:877-81. 10.1016/j.cmi.2017.11.011

21. Pituch H, Obuch-Woszczatyński P, Lachowicz D, et al.: Prevalence of Clostridium difficile infection in hospitalized patients with diarrhoea: results of a Polish multicenter, prospective, biannual point-prevalence study. Adv Med Sci. 2018, 63:290-95. 10.1016/j.advms.2018.03.003

22. DePestel DD, Aronoff DM: Epidemiology of Clostridium difficile infection. J Pharm Pract. 2013, 26:464-75. 10.1177/0897190013499521

23. Bauer KA, Johnston JEW, Wenzler E, et al.: Impact of the NAP-1 strain on disease severity, mortality, and recurrence of healthcare-associated Clostridium difficile infection. Anaerobe. 2017, 48:1-6. 10.1016/j.anaerobe.2017.06.009

24. Rao K, Micic D, Natarajan M, et al.: Clostridium difficile ribotype 027: relationship to age, detectability of toxins A or B in stool with rapid testing, severe infection, and mortality. Clin Infect Dis. 2015, 61:233-41. 10.1093/cid/civ254

25. Popoff MR, Rubin EJ, Gill DM, Boquet P: Actin-specific ADP-ribosyltransferase produced by a Clostridium difficile strain. Infect Immun. 1988, 56:2299-306.

26. Gerding DN, Johnson S, Rupnik M, Aktories K: Clostridium difficile binary toxin CDT: mechanism, epidemiology, and potential clinical importance. Gut Microbes. 2014, 5:15-27. 10.4161/gmic.26854

27. Warny M, Pepin J, Fang A, et al.: Toxin production by an emerging strain of Clostridium difficile associated with outbreaks of severe disease in North America and Europe. Lancet. 2005, 366:P1079-84. 10.1016/s01406736(05)67420-X

28. Akerlund T, Persson I, Unemo M, Norén T, Svenungsson B, Wullt M, Burman LG: Increased sporulation rate of epidemic Clostridium difficile Type 027/NAP1. J Clin Microbiol. 2008, 46:1530-33. 10.1128/jcm.01964-07

29. Cloud J, Noddin L, Pressman A, Hu M, Kelly C: Clostridium difficile strain NAP-1 is not associated with severe disease in a nonepidemic setting. Clin Gastroenterol Hepatol. 2009, 7:868-873.e2. 10.1016/j.cgh.2009.05.018

30. Morgan OW, Rodrigues B, Elston T, Verlander NQ, Brown DF, Brazier J, Reacher M: Clinical severity of Clostridium difficile PCR ribotype 027: a case-case study. PLoS One. 2008, 3:e1812-10. 10.1371/journal.pone.0001812

31. Walk ST, Micic D, Jain R, et al.: Clostridium difficile ribotype does not predict severe infection. Clin Infect 
Dis. 2012, 55:1661-68. 10.1093/cid/cis786

32. Sirard S, Valiquette L, Fortier LC: Lack of association between clinical outcome of Clostridium difficile infections, strain type, and virulence-associated phenotypes. J Clin Microbiol. 2011, 49:4040-46. 10.1128/jcm.05053-11

33. See I, Mu Y, Cohen J, et al.: NAP1 strain type predicts outcomes from Clostridium difficile infection. Clin Infect Dis. 2014, 58:1394-400. 10.1093/cid/ciu125

34. Hubert B, Loo VG, Bourgault AM, et al.: A portrait of the geographic dissemination of the Clostridium difficile North American pulsed-field type 1 strain and the epidemiology of C. difficile-associated disease in Québec. Clin Infect Dis. 2007, 44:238-44. 10.1086/510391

35. Hsu J, Abad C, Dinh M, Safdar N: Prevention of endemic healthcare-associated Clostridium difficile infection: reviewing the evidence. Am J Gastroenterol. 2010, 105:2327-39. 10.1038/ajg.2010.254

36. Wilcox MH, Gerding DN, Poxton IR, et al.: Bezlotoxumab for prevention of recurrent Clostridium difficile infection. N Engl J Med. 2017, 376:305-17. 10.1056/nejmoa1602615

37. FDA Approval of Bezlotoxumab in Prevention of Recurrent Clostridium difficile Infection . (2017). Accessed: January 12, 2019: http://www.jwatch.org/na43666/2017/04/24/fda-approval-bezlotoxumab-preventionrecurrent-clostridium.

38. Secore S, Wang S, Doughtry J, et al.: Development of a novel vaccine containing binary toxin for the prevention of Clostridium difficile disease with enhanced efficacy against NAP1 strains. PLoS One. 2017, 12:e0170640. 10.1371/journal.pone.0170640

39. Kokai-Kun JF, Roberts T, Coughlin O, et al.: The oral $\beta$-lactamase SYN-004 (ribaxamase) degrades ceftriaxone excreted into the intestine in phase 2a clinical studies. Antimicrob Agents Chemother. 2017, 61:pii: e02197-16. 10.1128/AAC.02197-16

40. López-Ureña D, Quesada-Gómez C, Miranda E, Fonseca M, Rodríguez-Cavallini E: Spread of epidemic Clostridium difficile NAP1/027 in Latin America: case reports in Panama. J Med Microbiol. 2014, 63:322-24. 10.1099/jmm.0.066399-0

41. Karlowsky JA, Adam HJ, Kosowan T, et al.: PCR ribotyping and antimicrobial susceptibility testing of isolates of Clostridium difficile cultured from toxin-positive diarrheal stools of patients receiving medical care in Canadian hospitals: the Canadian Clostridium difficile Surveillance Study (CAN-DIFF) 2013-2015. Diagn Microbiol Infect Dis. 2018, 91:105-11. 10.1016/j.diagmicrobio.2018.01.017

42. Martínez-Meléndez A, Tijerina-Rodríguez L, Morfin-Otero R, et al.: Circulation of highly drug-resistant Clostridium difficile ribotypes 027 and 001 in two tertiary-care hospitals in Mexico. Microb Drug Resist. 2018, 24:386-92. 10.1089/mdr.2017.0323

43. Coffman K, Chen XJC, Okamura C, Louie E: IVIG - A cure to severe refractory NAP-1 Clostridium difficile colitis? A case of successful treatment of severe infection, which failed standard therapy including fecal microbiota transplants and fidaxomicin. IDCases. 2017, 8:27-28. 10.1016/j.idcr.2017.03.002

44. Vickers RJ, Tillotson GS, Nathan R, et al.: Efficacy and safety of ridinilazole compared with vancomycin for the treatment of Clostridium difficile infection: a phase 2, randomised, double-blind, active-controlled, noninferiority study. Lancet Infect Dis. 2017, 17:735-44. 10.1016/S1473-3099(17)30235-9

45. Louie T, Nord CE, Talbot GH, et al.: Multicenter, double-blind, randomized, phase 2 study evaluating the novel antibiotic, cadazolid, in patients with Clostridium difficile infection. Antimicrob Agents Chemother. 2015, 59:6266-73. 10.1128/AAC.00504-15

46. Daley P, Louie T, Lutz JE, et al.: Surotomycin versus vancomycin in adults with Clostridium difficile infection: primary clinical outcomes from the second pivotal, randomized, double-blind, phase 3 trial. J Antimicrob Chemother. 2017, 72:3462-70. 10.1093/jac/dkx299

47. Aziz M, Chandrasekar VT, Desai M, Fatima R, Jackson M, Sharma P: Sa1858 - surotomycin (a novel antibiotic) vs vancomycin for Clostridium difficile infection: a systematic review and meta analysis. Gastroenterology. 2018, 154:S421. 